\title{
ANÁLISE DE INVESTIMENTO DE PROJETO COM APLICAÇÃO DE SIMULAÇÃO DE MONTE CARLO, PARA CONSTRUÇÃO DE REBOCADORES AZIMUTAIS
}

\author{
Mozart Caetano Heymann ${ }^{1}$ \\ mozart.mch@gmail.com \\ Ruben Huamanchumo Gutierrez ${ }^{1}$ \\ rubenhg@uol.com.br \\ Eduardo de Sá Fortes Leitão Rodrigues ${ }^{2}$ \\ edsafortes@gmail.com \\ Valdecy Pereira ${ }^{1}$ \\ valdecy.pereira@yahoo.com.br \\ Luiz Labruna ${ }^{3}$ \\ 1labruna@uol.com.br
}

${ }^{1}$ Universidade Federal Fluminense; Rua Passo da Pátria 156, Sl 309D, Niterói, RJ, 24210-240

${ }^{2}$ Universidade Federal Rural do Rio de Janeiro; Av. Governador Roberto Silveira s/no , S1 304

ADM, Moquetá - Nova Iguaçu - RJ, 26285-060

${ }^{3}$ Erres Shipping; Rua Teófilo Otoni 15, S1 814, Rio de Janeiro, RJ, 20090-080

\begin{abstract}
RESUMO
Este artigo tem por objetivo analisar a viabilidade de um projeto de investimento para construção de rebocadores com propulsão denominada azimutal, tecnologia que permite a movimentação dos rebocadores em todas as direções, proporcionando eficiência e segurança nas suas atividades, que são principalmente no apoio portuário auxiliando a entrada e a saída dos navios comerciais nos portos. Para a análise de decisão de investimento foi realizada uma apreciação convencional com modelos determinísticos, através do cálculo do valor presente líquido, conjugado com a taxa interna de retorno, que se constituem em ferramentas de avaliação sobre o fluxo de caixa do projeto. Em razão das incertezas de parâmetros do projeto, foram utilizados, modelos probabilísticos, valendo-se da Simulação de Monte Carlo, obtendo-se uma leitura do comportamento do modelo do projeto de forma mais realista. Ao final do estudo, os resultados das análises supracitadas demonstraram que o projeto é economicamente viável e, portanto, atende aos interesses de rentabilidade da empresa que irá implantá-lo, bem como aos anseios do mercado.
\end{abstract}

Palavras chave: Rebocador Azimutal; Tecnologia; Valor Presente Líquido; Taxa Interna de Retorno; Simulação de Monte Carlo.

\begin{abstract}
The objective of this paper is to analyze the viability of an investment project for the construction of tugboats with propulsion called azimuth, technology that allows the movement of tugs in all directions, providing efficiency and safety in its activities, which are mainly in port support assisting the entry and exit of commercial vessels in ports. For the analysis of the investment decision, a conventional evaluation with deterministic models was performed by calculating the net present value, combined with the internal rate of return, which constitute valuation tools on the cash flow of the project. Due to the uncertainties of the project parameters, probabilistic models were used, using the Monte Carlo Simulation, obtaining a more realistic reading of the behavior of the project model. At the end of the study, the results of the mentioned analyzes demonstrated that the project is economically viable and, therefore, meets the profitability interests of the company that will implement it, as well as the market's expectations.
\end{abstract}

Keywords: Azimuth Tugboat; Technology; Net Present Value; Internal Rate of Return; Monte Carlo Simulation. 


\section{Como Citar:}

HEYMANN, Mozart Caetano; GUTIERREZ, Ruben Huamanchumo; RODRIGUES, Eduardo de Sá Fortes Leitão; PEREIRA, Valdecy; LABRUNA, Luiz. Análise de Investimento de Projeto com aplicação de Simulação de Monte Carlo, para Construção de Rebocadores Azimutais. In: SIMPÓSIO DE PESQUISA OPERACIONAL E LOGÍSTICA DA MARINHA, 19., 2019, Rio de Janeiro, RJ. Anais [...]. Rio de Janeiro: Centro de Análises de Sistemas Navais, 2019.

\section{INTRODUÇÃO}

Com o mundo globalizado, o comércio internacional se transformou em grandes conglomerados e o intercâmbio se intensificou ainda mais, de modo que, o desenvolvimento das nações está atrelado ao que é adquirido e ao que é fornecido entre elas. Nesse contexto o transporte marítimo assume importância fundamental para o progresso das nações, e, por conseguinte, todos os serviços que possibilitam o ingresso dos navios comerciais são de suma importância para o segmento.

Assim, a viabilidade para que as embarcações comerciais cheguem aos portos, para a realização de carga e descarga dos produtos, depende da interação de um conjunto de fatores, tais como a profundidade da faixa marítima do porto (calado), a modernização do porto para efetuar com eficiência a movimentação da carga, e o atraque e desatraque das embarcações no berço portuário com segurança e rapidez [1].

As atividades de atraque e desatraque dos navios são realizadas com o auxílio de embarcações menores denominadas rebocadores, que atuam realizando esse serviço essencial de apoio portuário, para que os navios possam chegar e sair dos portos de forma eficiente e segura. Os rebocadores efetuam os serviços de apoio portuário não apenas com embarcações de carga, mas também de passageiros, além de efetuarem outros serviços, tais como, reboque de embarcações, transporte de equipamentos e salvatagem, sendo tais atividades reguladas pela Agência Nacional de Transportes Aquaviários (ANTAQ), segundo Resolução no 1766 de 23/07/2010, e suas alterações [2].

O objetivo principal do rebocador é puxar e empurrar embarcações de tamanho bem maior que ele próprio, portanto, tem como parâmetros importantes a potência e a força de tração estática, este conhecido pelo termo inglês "bollard pull" [3].

Assim sendo, um dos fatores primordiais no setor é o desenvolvimento tecnológico, e portanto, os rebocadores com propulsão convencional, que possuíam hélice fixo e leme, consequentemente com manobra limitada, perderam espaço para os rebocadores azimutais, cuja característica fundamental é possuir propulsores com atuação nos 360 graus do rebocador, sem precisarem de leme para governar, pois o propulsor faz esse papel, em razão da forte interação entre propulsão e direção, permitindo a essas embarcações navegarem, não só de proa, como de popa, ou mesmo de lado, propiciando a realização da operação em melhores condições de segurança e manobrabilidade [4]. Nessa conjuntura, as empresas foram impulsionadas a investirem na modernização e ampliação da frota, para atenderem as exigências de mercado.

Como assevera Rodrigues [5], todo investimento em um projeto, deve ser minuciosamente estudado, pois em linhas gerais, tem por objetivo a geração de riqueza para a empresa que irá empreendê-lo, e sempre sujeito há um risco intrínseco. Os fundamentos para a análise de investimento, conforme definido por Samanez [6], requer que o fluxo de caixa do projeto, seja corretamente modelado, atendendo as técnicas apropriadas e os parâmetros básicos do setor. Portanto, a avaliação relativa à viabilidade de implantação de um projeto de investimento requer o uso de ferramentas adequadas, que demonstrem o resultado esperado. 
Dentre os indicadores empregados para demonstração da viabilidade do projeto, neste trabalho foram utilizados o valor presente líquido (VPL) e a taxa interna de retorno (TIR), que consistem em metodologias determinísticas consagradas [6] e [7].

No entanto, por mais que as estimativas do fluxo de caixa representem os números do projeto, elas consistem em expectativas futuras que nem sempre ocorrem, e por isso, no bojo do projeto encontram-se presentes riscos e incertezas, que deverão ser identificados e, na medida do possível, serem empreendidas ações que minimizem os seus efeitos na implementação do projeto [7]. As técnicas utilizadas para o entendimento das incertezas constantes nos projetos de investimento referem-se a métodos probabilísticos que objetivam constatar os resultados diante de tais imprecisões [8]. Neste trabalho, será abordada à técnica da simulação de Monte Carlo, que tem como condão a interação das variáveis criticas, com grande número de simulações, mediante uma distribuição de probabilidade, para se constatar a convergência da viabilidade do projeto, diante dos vários cenários gerados nas simulações.

Este artigo tem por base a dissertação de Heymann [9], e está organizado da seguinte forma: A seção 2 define a metodologia da pesquisa e a modelagem utilizada. A seção 3 é dedicada a estabelecer o estudo de caso, descrevendo os parâmetros do projeto objeto de estudo. A seção 4 apresenta a discussão dos resultados dos indicadores aplicados na verificação da viabilidade do projeto. Por fim, a seção 5 conclui demonstrando a relevância desse trabalho não só no mundo acadêmico, mas também no cenário empresarial, bem como apresenta sugestões para pesquisas futuras.

\section{METODOLOGIA}

Para a tomada de decisão relativa a investimentos de capital de uma empresa requer-se uma análise detalhada dos parâmetros inerentes ao projeto que se quer desenvolver. Nesse sentido, é essencial que o orçamento de capital da empresa seja elaborado mediante a obtenção do maior número possível de informações relevantes, vez que determinados projetos comprometem substancialmente o capital da empresa, obrigando, muitas vezes, à obtenção de financiamentos, bem como podendo influenciar a sua flexibilidade de gestão, criando obstáculos para seus diversos setores e comprometendo o seu futuro. Portanto, o objetivo básico na decisão financeira relativo a um projeto é obter a maior rentabilidade possível sobre o investimento efetuado pelo proprietário, sem comprometer a liquidez da empresa [5]. A rentabilidade remete a expressão, valor atual de riqueza, que denota a ligação com o fator tempo, pois ao longo do tempo, o valor monetário do dinheiro não é estático. A associação entre maior retorno e maior sacrifício de liquidez ou tempo é evidente, pois um investimento de maior duração tem que estar associado a um maior retorno.

Assim, na análise de avaliação de um projeto, o fator tempo adquire importância preponderante no estudo de sua viabilidade, destacando-se os métodos de fluxos de caixa descontados, que se baseiam no conceito de valor do dinheiro no tempo ou valor atual [7].

$\mathrm{Na}$ montagem dos fluxos de caixa, é importante se observar pontos fundamentais, tais como enfatizado por Sanvicente [7], que devem ser consideradas as entradas e as saídas efetivas de caixa e, no exato momento em que ocorrem, caracterizando o regime de caixa, e uma das características fundamentais dos fluxos de caixa diz respeito ao conceito de incrementos das operações, ou seja, considera somente os valores associados às operações de investimento que estão sendo analisados, não contaminando com demais rubricas fora do objetivo do projeto.

Desta forma, seguindo as orientações descritas, modela-se um fluxo de caixa que melhor representa o projeto de investimento a ser implementado, e sobre ele se aplicam as ferramentas apropriadas, com cálculo de índices que irão retratar a viabilidade do projeto, no presente caso serão aplicados o valor presente líquido (VPL) e a taxa interna de retorno 
(TIR). Entretanto, verifica-se que, por mais que se estabeleça um modelo de fluxo de caixa atentando-se para todas as recomendações, e que este modelo seja representativo do projeto sob análise, não há como se prever integralmente o que poderá acontecer no futuro, seja pela própria imprevisibilidade, seja pela possibilidade de ocorrências alternativas. Visando prever o que poderá ocorrer diante destes fatos, são aplicadas técnicas de análise, como a simulação de Monte Carlo (SMC), para verificar o comportamento do projeto diante das varias situações imprevisíveis que poderão ocorrer.

Na sequência serão apresentados e analisados os métodos (VPL) e (TIR) que são os mais utilizados para medir a rentabilidade e avaliar a viabilidade econômica das alternativas de investimento, e a (SMC) para avaliar os riscos e incertezas inerentes a projetos de investimento.

\subsection{Método do valor presente líquido (VPL)}

Este método foi apresentado efetivamente, através da obra do renomado economista americano Irving Fisher [10], e expressa os fluxos do projeto em termos de valor monetário em uma mesma data, especificamente na data de início da análise. Portanto, ao avaliar uma alternativa de investimento representado por fluxo de caixa, utilizando este método, deve-se efetuar o cálculo dos eventos futuros constantes do fluxo a uma taxa de desconto a valor presente. Em suma, esse índice, mede o valor presente de fluxos de caixas gerados pelo projeto ao longo de sua vida útil [6]. O método é representado pelo símbolo VPL e definido pela expressão (1) abaixo:

$$
\begin{aligned}
\mathrm{VPL}=-\mathrm{I}+\Sigma_{\mathrm{t}}=1 \frac{\mathrm{FCxt}}{(1+\mathrm{K}) \mathrm{t}} \quad \text { critério de decisão para aceitação do projeto: } \\
\mathrm{V}>0 \rightarrow \text { projeto economicamente viável }
\end{aligned}
$$

Sendo:

I - investimento inicial;

$\mathrm{K}$ - custo de capital;

$\mathrm{t}$ - tempo que varia de 1 até $n$;

$\mathrm{FCx}_{\mathrm{t}}$ - representa os fluxos de caixa descontados ao período inicial;

$\Sigma$ - indica a soma da data 1 até a data $\mathrm{n}$ dos fluxos de caixa descontados ao período inicial.

Geralmente, nos projetos de investimento, é feito um desembolso inicial com o objetivo de recebimento de uma série de fluxos de caixa futuros e, neste sentido, a expressão acima traduz esses recebimentos futuros trazidos e somados na data zero, subtraídos do investimento inicial, gerando desta forma um valor presente líquido do investimento inicial [8]. Esse procedimento requer um fator para descontar os fluxos futuros, que é a taxa de desconto, a qual deve corresponder ao custo de capital [7].

Isto posto, fica claro conforme afirmado em [6], que o principio do VPL é encontrar alternativas de investimentos que valham mais do que o custo de capital, ou seja, as alternativas nas quais o VPL seja positivo, sendo este o critério de decisão da metodologia.

Deve ser aceito o projeto que apresentar VPL positivo, segundo elucida Rodrigues [5], por indicar que os fluxos de caixa foram suficientes para cobrir os custos e proporcionar uma taxa de retorno sobre o investimento inicial. Nessa condição, pode-se dizer que o investimento será recuperado, e remunerado na taxa de desconto que mede o custo de capital do projeto e gerará lucro extra, na data presente, no montante igual ao VPL, se positivo [8]. Ainda em [8], o autor complementa que uma das vantagens do método é apresentar um valor monetário para o projeto, correspondente ao montante do VPL, indicando se haverá aumento 
ou não do valor da empresa em função da decisão tomada sobre o investimento. Portanto, a utilização da metodologia, oferece um bom parâmetro de análise.

\subsection{Método da taxa interna de retorno (TIR)}

É a taxa de desconto que iguala o valor presente líquido do fluxo de caixa de um projeto a zero. Em outras palavras, a taxa que faz com que o valor atual das entradas seja igual ao valor atual das saídas [7].

Representado pelo símbolo TIR e definido pela expressão (2) abaixo:

$\mathrm{VPL}=-\mathrm{I}+\Sigma_{\mathrm{t}=1}^{\mathrm{n}} \stackrel{\text { FCxt }}{=0}$ critério de decisão para aceitação do projeto:

$(1+\mathrm{TIR}) \mathrm{t} \quad \mathrm{TIR}>\mathrm{K} \rightarrow$ projeto economicamente viável

Os parâmetros da expressão foram definidos no item relativo ao VPL, exceto a TIR definida neste item.

A regra de decisão neste método é que se a TIR for maior que o custo de oportunidade do capital, o projeto pode ser empreendido, pois significa que as aplicações da empresa estarão rendendo mais do que o custo dos recursos obtidos e utilizados na empresa como um todo [7].

A TIR quando comparada com o custo efetivo do capital de terceiros, permite analisar os efeitos da alavancagem de forma clara. Quando a TIR é maior que o custo efetivo dos capitais de terceiros, a contratação de dívidas provoca a elevação da rentabilidade dos capitais próprios. Ao contrário, ou seja, a TIR menor que o custo de capital de terceiros provoca uma redução da rentabilidade dos sócios.

Brealey e Myers [11] alertam que a aplicação da TIR como metodologia para avaliação de um projeto de investimento deve ser feita com cuidado, pois há casos, no qual o seu cálculo poderá ser distorcido, como exemplo em uma série de fluxo de caixa, chamados não convencionais, onde há mudanças de sinal ao longo do desenvolvimento do projeto, no qual poderá apresentar mais de uma taxa interna de retorno, devido à alternância do sinal do fluxo de caixa, e consequentemente não sendo um índice representativo do investimento.

\subsection{Análise de riscos e incertezas}

Os resultados esperados de um projeto de investimento estão sujeitos a incertezas, em razão da existência de diversos fatores fora do controle da administração da empresa, tais como, substituição tecnológica, novos concorrentes, demanda, comportamento da economia nacional e internacional, mudanças de política regulatória do mercado, variações climáticas, dentre outros fatores relevantes [7].

A incerteza se caracteriza pela ocorrência de resultados exequíveis, sem qualquer vínculo com uma determinada distribuição de probabilidade. O risco, distinto da incerteza, caracteriza-se pela presença de resultados possíveis, com probabilidades associadas aos diferentes resultados.

O economista inglês Frank H. Knight [12], descreve a diferença entre ambos da seguinte forma:

“a) Risco: quando as variáveis encontram-se sujeitas a uma distribuição de probabilidades conhecidas (ou que pode ser calculada com algum grau de precisão). Em outras palavras: representa uma incerteza que pode ser medida.

b) Incerteza: quando esta distribuição de probabilidades não pode ser avaliada (envolve situações de ocorrência não repetitiva). Em outras palavras: consiste em um risco que não pode ser avaliado". 
De acordo com o descrito por Bruni [8], na análise de incertezas e de riscos utilizam-se técnicas para se alcançar valores segundo determinados critérios nos casos de incertezas, e valores esperados nos casos de riscos.

Objetivando permitir certa margem de segurança na execução do projeto, para se alcançar uma decisão mais acertada, em razão da não garantia de precisão que as estimativas do fluxo de caixa possuem, utilizam-se técnicas que possibilitam ao gestor uma visão mais acurada da sensibilidade do empreendimento, face às alterações nas principais variáveis, incluindo cenários imprevisíveis.

Uma das técnicas principais para dirimir o descrito acima é a simulação de Monte Carlo, que será descrita na sequência.

\subsubsection{Simulação de Monte Carlo}

Este método apresenta como vantagem como se verifica em [11], a possibilidade de considerar grande número de combinações possíveis da distribuição de probabilidades dos parâmetros que estão sendo analisados e que condicionam as decisões. Tais parâmetros analisados são as variáveis-chaves sensibilizadas a partir de uma distribuição de probabilidades que irá demonstrar o comportamento do modelo representativo do projeto, a partir de um número considerável de simulações.

Assim, é possível analisar vários aspectos de mercado, de custos, sensibilidade dos preços, de vida útil dos equipamentos e outros parâmetros essenciais, a partir da distribuição de probabilidades das variáveis-chave, para decidir sobre determinado plano de investimento $[6]$.

Uma das vantagens do método é inerente à exigência da especificação das interligações entre as variáveis, assinalando a forma como as variáveis estão relacionadas e como afetam o resultado do projeto quando as variáveis relevantes são alteradas aleatoriamente, possibilitando maior entendimento do projeto e, consequentemente, melhorando sua qualidade ou rentabilidade [6] e [11].

Os principais passos a serem seguidos na simulação de um projeto de investimento, de acordo com as obras supracitadas, são:

a. Modelagem do projeto - consiste na definição das variáveis e equações para estabelecer o fluxo de caixa representativo do projeto. As equações devem refletir as interdependências entre as variáveis.

b. Especificação das probabilidades de desvio das previsões - realizada para cada parâmetro crítico, bem como a sua magnitude.

c. Selecionar números para os desvios de previsão e calcular os fluxos de caixa efetuada a combinação aleatória entre os valores das distribuições dos desvios da previsão das variáveis e, em seguida, são calculados os fluxos de caixa resultantes. Nesse contexto, é relevante repetir o procedimento por um número considerável de vezes, até obter uma distribuição de resultados com a maior precisão possível, em geral VPL ou TIR do projeto.

Pelo descrito acima, verifica-se conforme ressaltado em [8], que a criação de um modelo para a prática de simulações requer o emprego de números aleatórios que funcionam como sementes iniciais. São utilizados equipamentos de processamentos de dados para operacionalizar o método, objetivando velocidade na geração e simulações, bem como a criação de números aleatórios eletronicamente. A expressão (3) retrata o método, para uma distribuição com um limite superior e um limite inferior:

$$
\mathrm{a}+\{(\mathrm{b}-\mathrm{a}) \mathrm{x}[\text { ALEATÓRIO }(\mathrm{)})]\}
$$


Sendo:

$\mathrm{a}=$ limite inferior

$\mathrm{b}=$ limite superior

ALEATÓRIO( ) = função do programa computacional MS Excel que gera números randômicos entre 0 e 1, distribuídos uniformemente.

Existem outras formas de cálculo de acordo com a distribuição das variáveis que serão sensibilizadas para realização da simulação.

Titman e Martin [13] apresentam a distribuição de probabilidade triangular, como vantajoso, uma vez que leva em consideração os valores máximo, mínimo e mais provável da distribuição, enquanto que a tradicional distribuição uniforme considera apenas os valores máximos e mínimos. Desta forma, como ressaltam os autores, na distribuição triangular os modelos são flexíveis, podendo os seus parâmetros serem ajustados para captar distribuições tanto simétricas, quanto assimétricas.

A expressão que define a distribuição triangular, utilizando as ferramentas do programa computacional MS Excel, é apresentada em [14], e corresponde a expressão (4):

$$
\begin{aligned}
& \mathrm{a}+\left\{(\mathrm{b}-\mathrm{a}) \times\left[\operatorname{ALEATÓRIO}_{1}()+\operatorname{ALEATÓRIO}_{2}()\right] / 2\right\} \\
& \text { Sendo: } \\
& \mathrm{a}=\text { limite inferior } \\
& \mathrm{b}=\text { limite superior } \\
& \text { ALEATÓRIO }() \text { = função do programa computacional MS Excel que gera } \\
& \quad \text { números randômicos entre } 0 \text { e } 1 \text {, distribuídos uniformemente. }
\end{aligned}
$$

A simulação de Monte Carlo, trata-se de uma grande ferramenta de análise do comportamento das variáveis críticas e suas interdependências no modelo representativo, tanto que esta técnica é utilizada não só em finanças, como em vários ramos da ciência, tais como na engenharia, medicina, entre outros [8].

\section{ESTUDO DE CASO}

\subsection{Apresentação do projeto}

O estudo de caso será a análise do projeto de investimento da empresa Domar Rebocadores S.A. (empresa fictícia), para construção de dez rebocadores azimutais com 70 TTE (toneladas de tração estática), em inglês, bollard pull.

A construção dos dez rebocadores responde às necessidades do mercado no que tange ao atributo tecnológico da frota de propulsão azimutal, para atender principalmente, aos portos de grande movimentação e que tenham deficiência de rebocadores.

Cabe ressaltar que as características técnicas dos rebocadores projetados permitem que eles sejam operados em todos os portos do litoral brasileiro, o que lhes confere a flexibilidade necessária para assumir qualquer posição, que logística e economicamente, seja de interesse da empresa e do mercado.

Esse projeto será realizado, através de financiamento com recursos do Fundo Marinha Mercante (FMM), sendo o agente financeiro o Banco Nacional de Desenvolvimento Social (BNDES), responsável pelo repasse dos valores aprovados pelo FMM.

Os recursos subsidiados do FMM têm por objetivo desenvolver a indústria da construção naval nacional, e para a obtenção de tais recursos é necessário o cumprimento de uma série de exigências, tanto pelo estaleiro construtor, como pelo contratante, conforme a Lei 10.893 de 13/07/2004 e suas alterações e, Portaria MT/GM nº 253 de 2009 [2]. 
A aquisição da prioridade de financiamento junto ao FMM inicia-se com a apresentação de um projeto de viabilidade econômico-financeira e social. Um projeto desta envergadura gera aproximadamente 300 empregos diretos e 400 indiretos durante as obras, além da criação de cerca de 100 empregos para a operação dos rebocadores.

$\mathrm{O}$ aspecto do meio ambiente também é fundamental, tanto que um dos requisitos iniciais é que o estaleiro construtor tenha licença de operação para construção expedida pelo Instituto Estadual do Ambiente (INEA), além de outras recomendações inerentes aos aspectos de sustentabilidade ligado ao meio ambiente, saúde e segurança do trabalho. Ou seja, somente uma empresa estruturada é que tem acesso a este tipo de financiamento.

O prazo previsto de conclusão da construção dos rebocadores relativos ao projeto é de 60 meses (cinco anos) e os rebocadores entrarão em operação assim que forem entregues, Os dois primeiros têm previsão de entrega para 12 meses após o início da implementação do projeto, e a cada 12 meses subsequentes serão construídos dois rebocadores de cada vez.

As receitas para as embarcações do projeto foram previstas com base nas características do mercado relativas a rebocadores com as mesmas especificações do caso sob análise [15], chegando ao valor médio de $\mathrm{R} \$ 7.500,00$ (sete mil e quinhentos reais) por faina. Uma faina corresponde a atividade de um rebocador. Considerando-se um equilíbrio estável da demanda com a oferta do mercado de rebocadores, o volume de atividade operacional médio por rebocador similar corresponde a 1.300 fainas por ano, que equivale à execução de três a quatro fainas por dia, número factível para a realidade atual [17]. Vale lembrar que uma faina corresponde a uma operação realizada por um rebocador, e que, para realizar uma manobra em geral, são utilizados no mínimo dois rebocadores (duas fainas), e cada manobra dura, em média, 1,5 h, portanto, a atividade definida é condizente, e será adotado como base para esse projeto.

Os custos se subdividem em variáveis que alteram de acordo com a atividade operacional do rebocador, os fixos que incidem independente da atividade operacional, e os administrativos correspondentes à gestão e apoio das operações. $\mathrm{Na}$ sequência segue o resumo dos dados do projeto.

\subsection{Dados do projeto para análise da rentabilidade}

A rentabilidade do projeto será calculada a partir da elaboração do fluxo de caixa, com base nos critérios descritos nas seções anteriores.

Os dados do projeto foram estabelecidos com base nos parâmetros de mercado, em condições similares ao tipo de rebocadores empregados e aos portos nos quais os rebocadores poderão atuar. Para tanto, foram utilizadas as informações de documentos públicos tais como: relatórios anuais de empresas do setor [15], priorizações de construções em reunião do Conselho Diretor do Fundo de Marinha Mercante [16], dentre outros. Inclusive entrevistas com especialista do setor [17].

A seguir os principais dados anuais de entrada do modelo de projeção:

a. serão construídos dois rebocadores por ano. No fluxo de caixa para análise do investimento, a previsão de receita e do custo será com base nessa premissa;

b. a receita bruta gerada por um rebocador corresponde ao número de fainas, nesse caso previsto 1.300 (ano), multiplicado pelo valor do preço médio de venda de $\mathrm{R} \$ 7.500,00$, gerando receita bruta de $\mathrm{R} \$ 9.750 .000,00$;

c. os impostos redutores da receita são PIS, COFINS e ISS. ,Os dois primeiros definidos pela Lei Federal 9.718 / 98, e o ISS, através de Lei Municipal de acordo com o local da operação. O total incidente sobre a receita bruta é de $14,25 \%$, ficando a receita líquida correspondente $85,75 \%$ da receita bruta; 
d. os custos variáveis são os custos diretos atrelados ao nível de atividade, variam quando o nível de produção varia [18]. No caso compreende o consumo de combustível, de lubrificantes, manutenção, docagem, e outros de menor valor. Os desembolsos de combustível e docagem respondem por $80 \%$ desses custos. Esses custos foram apurados com base de mercado, e utilizando os preços atualizados, resultou no custo unitário de aproximadamente $\mathrm{R} \$ 1.325,00$ por faina, alcançando o limite de $\mathrm{R} \$ 1.523,00$ por faina, de acordo com o tempo de vida útil do rebocador, em decorrência da agregação da variação crescente dos valores de manutenção e docagem, este realizado a cada 5 anos, por força de agentes reguladores, objetivando garantir as boas condições de navegabilidade da embarcação no que tange a segurança e preservação da vida útil. O valor total no $1^{\circ}$ ano por rebocador será R\$ 1.722.000,00.

e. os custos fixos são os custos que incidem independentemente dos rebocadores operarem ou não, ou seja, não variam com o nível de produção e só podem ser eliminados se a empresa encerrar suas atividades [18]. No caso compreende a folha de pagamento das tripulações, suprimentos, infracostagem, certificações, seguros e outros de menor monta. Sendo que o desembolso com as tripulações e respectivos encargos equivale aproximadamente $85 \%$ desses custos, haja vista que a embarcação fica tripulada 24 horas, todos os dias. $O$ valor total anual apurado corresponde a R $\$ 1.240 .000,00$ por rebocador;

f. a depreciação anual por rebocador corresponde a $\mathrm{R} \$ 1.971 .500,00$, obtido pela aplicação da taxa de 6,67 \% aa., considerando a vida útil de 15 anos. Apesar de ser um custo fixo, encontra-se destacado daquela rubrica, para fins de modelagem do fluxo de caixa, por ser item não monetário, portanto terá tratamento especial, conforme descrito mais adiante;

g. as despesas administrativas que englobam o pessoal do staff, aluguel da sede e filiais, leasing de veículos, e demais para gestão do negócio. Correspondem a $\mathrm{R} \$ 3.305 .000,00$ por ano, havendo acréscimo no ingresso de cada novo lote de dois rebocadores, no montante aproximado de R $\$ 290.000,00$ por ano, estabilizando após o ingresso de todos;

h. as despesas de comercialização correspondem a $0,5 \%$ do faturamento bruto;

i. sobre o lucro apurado incide a Contribuição Social (CS), com alíquota de $9 \%$ e o Imposto de Renda (IR), com 15\%, mais o adicional de $10 \%$ sobre o que exceder do montante de $\mathrm{R} \$ 240.000,00$ no ano [19];

j. A partir do Lucro apurado, após a incidência de IR e CS são realizadas inclusões e exclusões como as abaixo relacionadas, para a apuração do fluxo de caixa livre, de acordo com [20]:

- retorno do valor da depreciação, por se tratar de item não monetário;

- inclusão da variação de capital de giro necessário para atividades da empresa, tendo como base de cálculo o correspondente a $10 \%$ da variação da receita bruta de um ano para outro, como desembolso;

- lançamento do valor anual de financiamento do FMM, como desembolso;

k. Apesar de não ser objeto de discussão deste trabalho, também foi calculado o fluxo de caixa do acionista, conforme indicado em [6], considerando as seguintes inclusões e exclusões abaixo listadas: 
- retorno do valor do financiamento do FMM,

- desembolso das prestações pagas do financiamento,

- desembolso do benefício fiscal sobre os juros de financiamento.

O valor de investimento para a construção de cada rebocador, segundo proposta do estaleiro construtor, foi estipulado em $\mathrm{R} \$ 29.572 .162,56$, ficando o valor total do projeto para a construção dos dez rebocadores, igual a $\mathrm{R} \$ 295.721 .625,60$.

O financiamento do FMM foi de $90 \%$ do total de cada rebocador, correspondendo a $\mathrm{R} \$ 26.614 .946,30$, ficando o valor total de financiamento para os 10 rebocadores o montante de $\mathrm{R} \$ 266.149 .463,04$.

No tocante às questões de financiamento, destacam-se aspectos tais como:

- desembolsos mensais de acordo com os controles junto ao agente financiador, através do Quadro de Usos e Fontes (QUF), que é o detalhamento de todo o projeto, sendo definido no momento da aprovação do financiamento, e corresponde ao documento de controle físico-financeiro do projeto;

- construção de dois rebocadores a cada 12 meses;

- juros de 3,5\%, sobre o saldo devedor;

- pagamento em 16 anos, com 1 ano de carência, a partir do final da construção de cada rebocador, sistema de tabela price.

O custo de oportunidade do investimento foi fixado em $10 \%$ a.a.[17], que corresponde à taxa de desconto normalmente empregada para projetos desta natureza, e aceita pelos agentes financeiros. Não será considerada a atualização monetária e nem aumento de demanda.

\subsection{Modelo do fluxo de caixa}

Para elaboração do fluxo de caixa, as premissas foram descritas anteriormente, observando-se a metodologia explanada nas seções anteriores e o modelo proposto em [6], sendo feita uma projeção de 20 anos, que corresponde ao término de pagamento do financiamento do projeto dos dois últimos rebocadores.

O procedimento inicia com o lançamento dos dados disponíveis em planilhas auxiliares para prepará-los com detalhes, e posteriormente, consolidados e vinculados à planilha do fluxo de caixa, cujos primeiros 5 anos encontra-se a seguir, no quadro 1 .

Quadro 1 - Fluxo de Caixa do projeto de investimento (em Milhares de Reais)

\begin{tabular}{|c|c|c|c|c|c|c|c|c|}
\hline Referência & $\mathbf{0}$ & 1 & 2 & 3 & 4 & 5 & 6 a 19 & 20 \\
\hline Anos & 2.019 & 2.020 & 2.021 & 2.022 & 2.023 & 2.024 & & 2.039 \\
\hline Preço por faina & & 7,50 & 7,50 & 7,50 & 7,50 & 7,50 & & 7,50 \\
\hline Demanda - numero de fainas & & 1.300 & 1.300 & 1.300 & 1.300 & 1.300 & & 1.300 \\
\hline Quant. de rebocadores concluídos & & 2 & 4 & 6 & 8 & 10 & & 10 \\
\hline Receitas operacionais & & $19.500,00$ & $39.000,00$ & $58.500,00$ & $78.000,00$ & $97.500,00$ & & $97.500,00$ \\
\hline Deduções da Receita & & $(2.778,75)$ & $(5.557,50)$ & $(8.336,25)$ & $(11.115,00)$ & $(13.893,75)$ & & $(13.893,75)$ \\
\hline Receita Liquida & & $16.721,25$ & $33.442,50$ & $50.163,75$ & $66.885,00$ & $83.606,25$ & & $83.606,25$ \\
\hline Custos variáveis & & $(3.444,56)$ & $(6.889,12)$ & $(10.333,68)$ & $(13.778,24)$ & $(17.222,80)$ & & $(19.794,80)$ \\
\hline Custos fixos & & $(2.479,56)$ & $(4.959,12)$ & $(7.438,69)$ & $(9.918,25)$ & $(12.397,81)$ & & $(12.397,81)$ \\
\hline Depreciação & & $(3.942,96)$ & $(7.885,91)$ & $(11.828,87)$ & $(15.771,82)$ & $(19.714,78)$ & & - \\
\hline Despesas administrativas e comerciais & & $(3.305,02)$ & $(3.594,52)$ & $(3.884,02)$ & $(4.308,52)$ & $(4.586,02)$ & & $(4.586,02)$ \\
\hline Lucro Operacional ou LAIR & & $3.549,15$ & $10.113,82$ & $16.678,50$ & $23.108,17$ & $29.684,84$ & & $46.827,62$ \\
\hline Imposto de Renda & & $(863,29)$ & $(2.504,46)$ & $(4.145,62)$ & $(5.753,04)$ & $(7.397,21)$ & & $(11.682,90)$ \\
\hline Contribuição Social & & $(319,42)$ & $(910,24)$ & $(1.501,06)$ & $(2.079,74)$ & $(2.671,64)$ & & $(4.214,49)$ \\
\hline Lucro apos IR ou LAPIR & & $2.366,44$ & $6.699,12$ & $11.031,81$ & $15.275,39$ & $19.616,00$ & & $30.930,23$ \\
\hline Depreciação & & $3.942,96$ & $7.885,91$ & $11.828,87$ & $15.771,82$ & $19.714,78$ & & - \\
\hline Variações no capital de giro & $(1.950,00)$ & $(1.950,00)$ & $(1.950,00)$ & $(1.950,00)$ & $(1.950,00)$ & - & & $9.750,00$ \\
\hline Investimentos & $(59.144,33)$ & $(59.144,33)$ & $(59.144,33)$ & $(59.144,33)$ & $(59.144,33)$ & - & & - \\
\hline Fluxo de Caixa Liquido & $(61.094,33)$ & $(54.784,93)$ & $(46.509,29)$ & $(38.233,65)$ & $(30.047,11)$ & $39.330,77$ & & $40.680,23$ \\
\hline
\end{tabular}

Fonte: Dados do Projeto. 
Definido o fluxo de caixa, partiu-se para o cálculo dos indicadores de viabilidade do projeto, sob o ponto de vista determinístico e probabilístico, cujos resultados serão discutidos na próxima seção.

\section{DISCUSSÃO DOS RESULTADOS}

\subsection{Avaliação pelo método do Valor Presente Líquido (VPL)}

O cálculo do VPL foi elaborado com auxílio do programa computacional MS Excel, através da função VPL, que corresponde à expressão (1) aplicada sobre os dados da planilha do fluxo de caixa do projeto.

O VPL do fluxo de caixa livre (FCL) do projeto equivale ao valor positivo de $\mathrm{R} \$ 4.548 .806,73$ indicando que o projeto é economicamente viável, pois conforme os ditames do método esse resultado positivo, representa o ganho do valor monetário, descontado o custo de capital, no caso de $10 \%$, sendo, portanto, um retorno de valor monetário considerável.

Embora, o VPL seja um indicador primordial na avaliação de projetos de investimentos, os estudiosos da administração financeira defendem que, não é conveniente a aceitação de um projeto de investimento, por um único índice. Assim sendo, a seguir, é apresentada a avaliação do projeto em análise, por meio de outro índice complementar.

\subsection{Avaliação pelo método da Taxa Interna de Retorno (TIR)}

O cálculo da TIR também foi efetuado com auxílio do programa computacional MS Excel, através da função TIR, que corresponde à expressão (2), aplicada sobre os dados da planilha do fluxo de caixa do projeto.

A apuração da TIR sobre o FCL, resultou na taxa de $10,28 \%$, acima do custo de oportunidade de $10 \%$, indicando a viabilidade do projeto, de acordo com os preceitos da metodologia.

Importante ressaltar que no caso sob estudo, a TIR apresenta-se aplicável, pois o FCL é do tipo convencional, com valores negativos iniciais e positivos na sequência, por conseguinte, apresentando um resultado único.

Considerando-se os resultados obtidos pelos dois métodos acima abordados, fica patente a viabilidade do projeto. O gráfico 1 apresenta a curva representativa da correlação entre VPL e TIR, e variação do VPL de acordo com as taxas de desconto.

Gráfico 1 - Curva da Taxa Interna de Retorno do projeto de investimento

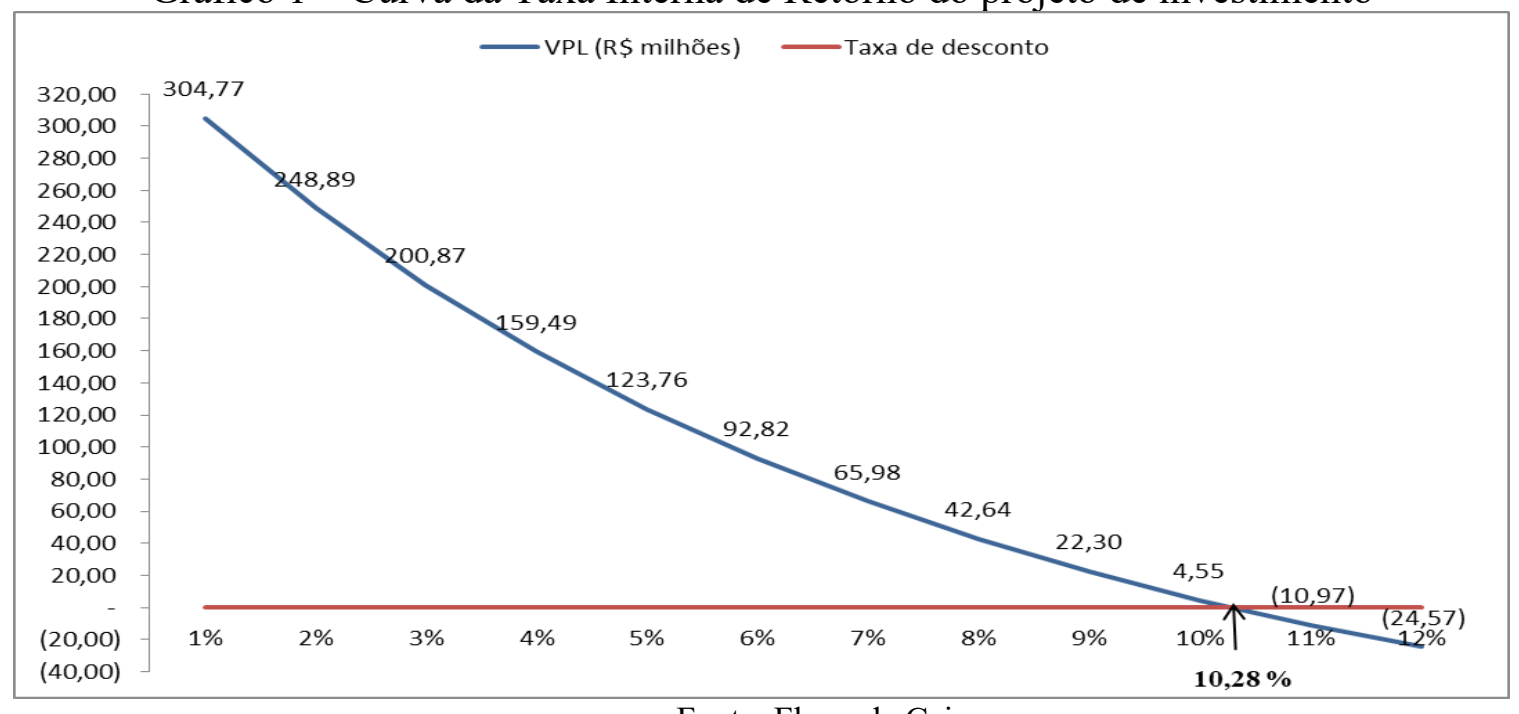

Fonte: Fluxo de Caixa. 


\subsection{Análise de incertezas - Simulação de Monte Carlo (SMC)}

Tratando-se de um projeto desta magnitude, a existência de incertezas é patente, e por mais que sejam minimizadas, em razão da experiência do mercado e pelas previsões factíveis, não há como eliminá-las.

Inicialmente é necessário identificar as variáveis críticas do projeto. No caso em pauta, o preço do serviço e a atividade operacional, são os parâmetros formadores da receita, e a fixação de ambos depende de uma série de fatores, inclusive externos, como é o caso da atividade operacional dependente do comércio internacional, que é a mola mestra que determina a demanda, bem como a captação de clientes para garantir a atividade operacional prevista. Da mesma forma o preço praticado pode oscilar, não trazendo, assim, garantia de sua manutenção, pois depende das forças de mercado. Assim sendo, além de serem parâmetros críticos, tendem a serem imprevisíveis.

Desta forma, levando-se em consideração que o preço e a demanda, em razão da relevância e da incerteza da ocorrência do valor previsto, causa insegurança na condução do projeto, faz-se necessário realizar a avaliação através de técnicas que permitam ao gestor entender as alternativas viáveis que poderão ocorrer ao longo de sua implementação, e possibilitar a mitigação das consequências que poderão surgir em face das incertezas existentes. Para tanto, dentre as técnicas possíveis, no presente trabalho será aplicada a simulação de Monte Carlo.

\subsubsection{Avaliação pela Simulação de Monte Carlo (SMC)}

O ponto de partida é a identificação das variáveis críticas, já definidas anteriormente como sendo o preço de venda do serviço e a atividade operacional.

Para a simulação dos preços, utilizou-se a distribuição de probabilidade triangular, uma vez que se leva em consideração os valores máximo, mínimo e mais provável da distribuição, enquanto que a tradicional distribuição uniforme considera apenas os valores máximos e mínimos.

Conforme definido na seção 3, o preço médio praticado por faina é de $\mathrm{R} \$ 7.500,00$. Para fins de simulação foi definida uma variação de $10 \%$ para cima e para baixo, ficando o limite superior equivalente a $\mathrm{R} \$ 8.250,00$, e o inferior igual a $\mathrm{R} \$ 6.750,00$. Com auxílio do programa computacional MS Excel, através da expressão (4) foram geradas 1.000 simulações de preço por ano, nos limites definidos acima.

A simulação do número de fainas vendidas (atividade operacional), valeu-se da distribuição de probabilidade discreta, pelo motivo inerente da própria variável, que admite somente números inteiros positivos. Nesta metodologia, definiu-se quais são as variações aceitáveis e qual a probabilidade delas ocorrerem. No caso em tela, foram considerados dois níveis de variação de 100 fainas para cima e para baixo, a partir do número previsto de 1.300 fainas, e estipulada à probabilidade de ocorrência de cada hipótese, com base no mercado, e de forma conservadora atribuindo menores pesos para os valores acima do esperado. A distribuição encontra-se representada no quadro 2, abaixo.

Quadro 2 - Distribuição de probabilidade da atividade operacional

\begin{tabular}{|c|c|}
\hline $\begin{array}{c}\text { Número de fainas } \\
\text { vendidas no ano }\end{array}$ & Probabilidades \\
\hline 1100 & $\mathbf{0 , 1 0}$ \\
1200 & $\mathbf{0 , 2 5}$ \\
1300 & $\mathbf{0 , 4 0}$ \\
1400 & $\mathbf{0 , 2 0}$ \\
1500 & $\mathbf{0 , 0 5}$ \\
\hline
\end{tabular}

Fonte: Próprio Autor. 
Utilizando-se a geração de números aleatórios do programa computacional MS Excel, foi gerado 1.000 simulações para cada ano, considerando a distribuição de entrada do quadro acima, obtendo-se a distribuição aleatória do número de fainas.

$\mathrm{Na}$ continuidade, também usando o sistema MS Excel, foi reproduzido o fluxo de caixa livre, com os parâmetros próprios, e inserido para cada ano os valores correspondentes das simulações obtidas para o preço e para a atividade operacional, gerando a receita bruta. Com base nos resultados apurados, calculou-se o VPL para cada linha, obtendo-se, consequentemente, 1.000 indicadores de VPL, destes $66 \%$ positivos, indicando convergência para VPL positivo, demonstrando a viabilidade do projeto.

Na sequência, através da ferramenta do programa computacional MS Excel, função complementar Estatística Descritiva, foi realizada a apuração de indicadores estatísticos, gerando o quadro 3, a seguir.

Quadro 3 - Resultados estatísticos da simulação

\begin{tabular}{|l|r|}
\hline \multicolumn{2}{|c|}{ Estatistica Descritiva } \\
\hline Média & $1.877 .647,81$ \\
Erro padrão & $207.488,33$ \\
Mediana & $1.755 .693,59$ \\
Modo & \#N/D \\
Desvio padrão & $6.561 .357,08$ \\
Variância da amostra & $4,31 \mathrm{E}+13$ \\
Curtose & $(0,14)$ \\
Assimetria & 0,12 \\
Intervalo & $37.197 .016,95$ \\
Mínimo & $(15.236 .292,96)$ \\
Máximo & $21.960 .723,99$ \\
Soma & $1,88 \mathrm{E}+09$ \\
Contagem & $1.000,00$ \\
Nível de confiança $(95,0 \%)$ & $407.162,95$ \\
\hline
\end{tabular}

Fonte: MS Excel - Função Estatística Descritiva.

Analisando as informações constantes no quadro 3, com fundamento em [21] e [22], tem-se:

a) a média de VPL das simulações equivale a R $\$ 1.877 .647,81$, indicando uma tendência positiva do VPL num patamar razoável;

b) o VPL máximo é $\mathrm{R} \$ 21.960 .723,99$ e o mínimo negativo de - $\mathrm{R} \$ 15.236 .292,96$, correspondem, respectivamente, ao melhor e pior resultado dentre toda a simulação, havendo um peso maior para o limite máximo;

c) o VPL para o nível de confiança de 95\% apresenta o limite superior de $\mathrm{R} \$ 2.284 .810,76$ e o limite inferior de $\mathrm{R} \$ 1.470 .484,86$, ambos positivos, obtidos a partir do resultado da média, respectivamente, somada e subtraída do valor do nível de confiança;

d) avaliando o índice de assimetria, maior que zero, e de pouca monta, constata-se que se trata de uma distribuição de pequena assimetria positiva, sendo a variação entre a média e a mediana de $6,95 \%$, que é baixa;

e) o índice de curtose negativo indica que a distribuição dos valores obtidos é leptocúrtica; são curvas mais afiladas, com valores menos dispersos da média, ou seja, os intervalos de confiança são menores, portanto, mais interessante que a sua oposta platicúrtica, que apresenta valores mais dispersos da média; 
f) A dispersão relativa é dada pelo coeficiente de variação, que corresponde à razão entre o desvio padrão e a média, no caso em pauta $\mathrm{CV}=3,50$. Na presença de um projeto concorrente, este indicador poderá ser usado na comparação de riscos relativos.

O histograma, gráfico 2, é a representação gráfica da distribuição de frequências dos dados, obtidos com a simulação. Nota-se nele que a distribuição é relativamente simétrica, maior concentração próximo à média, conforme havia sido destacado anteriormente. Constata-se também pela curva de frequência acumulada que a partir de 34\% os VPLs são positivos, portanto, evidenciando que $66 \%$ dos VPLs são positivos, indicando que o risco é relativamente baixo para a implementação do projeto.

\section{Gráfico 2 - Histograma resultante da simulação}

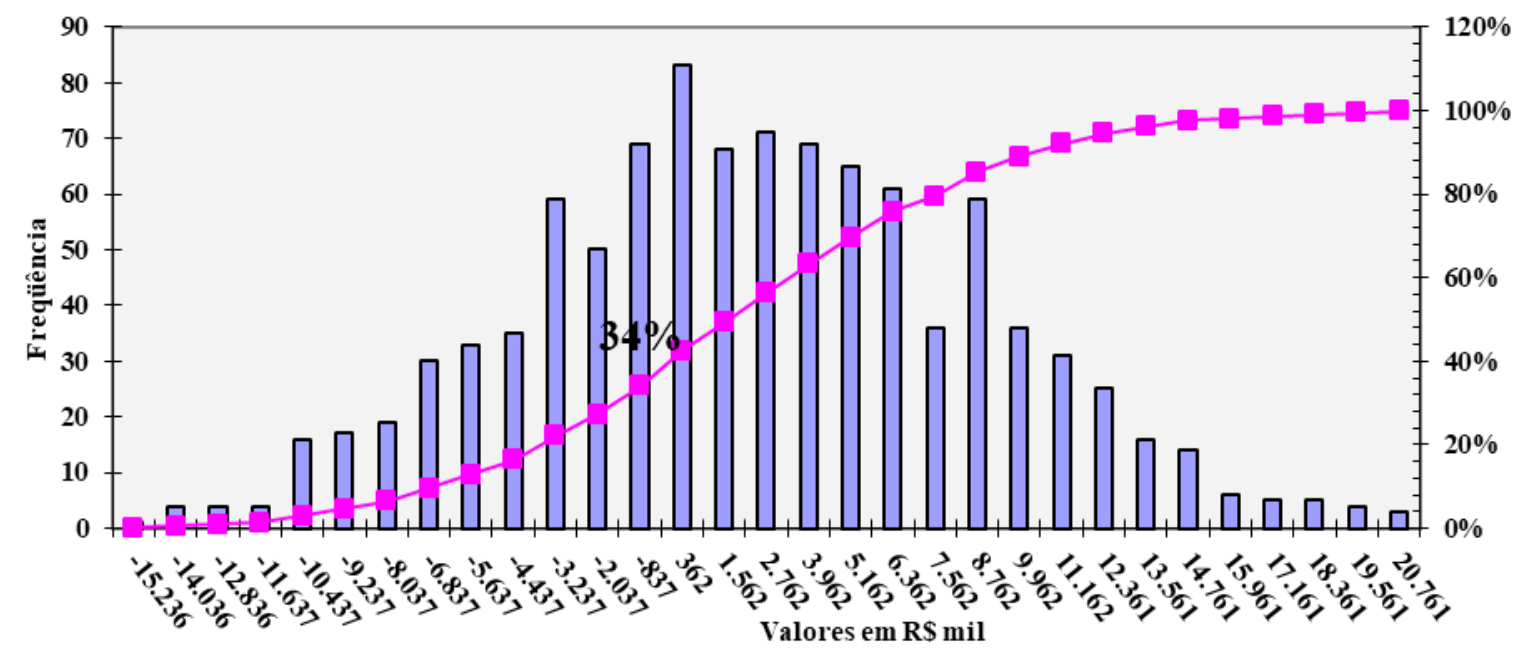

Fonte: Resultados de VPLs da simulação.

\section{CONCLUSÕES}

O objeto deste trabalho se ateve à análise de investimento do projeto de construção de dez rebocadores azimutais, definido pelo planejamento estratégico do grupo econômico da empresa Domar Rebocadores S.A..

Nessa área da navegação, os valores envolvidos, geralmente, são de grande porte. No caso concreto, o investimento correspondeu a $\mathrm{R} \$ 295.721 .625,60$, razão pela qual a captação de $90 \%$ desse valor foi realizada através de financiamento subsidiado pelo Fundo da Marinha Mercante (FMM), por meio do agente financeiro BNDES, como forma de promover o desenvolvimento da construção naval. Por meio desta política de financiamento, o Brasil pode avançar neste mercado de navegação, que conforme já assinalado nas considerações iniciais, é a mola mestra do comércio marítimo, no qual rebocadores atuam de maneira intensa realizando as manobras de atracação e desatracação dos navios comerciais, e o país com cerca de 7,5 mil km de costa, tem toda vocação para o segmento marítimo.

Cabe ressaltar a relevância dessa iniciativa na questão social com a geração de empregos, de aproximadamente 700 postos diretos e indiretos no decurso das obras, além de outros necessários à operação dos rebocadores. Nesse sentido, cabe igualmente ressaltar a questão do meio ambiente, pois é exigido, dentre outros requisitos inerentes a este tema, que o estaleiro construtor tenha licença de operação para a construção, expedida pelo Órgão Público Ambiental. Por conseguinte, para as empresas terem acesso aos recursos subsidiados 
do FMM, devem ser estruturadas no que se refere à sustentabilidade e à segurança do trabalho.

Foram empregadas metodologias tradicionais de avaliação de investimento para tomada de decisão, conhecidas como modelos determinísticos, constatando-se, a partir das ferramentas empregadas, que o projeto era viável economicamente, respaldado pelos resultados obtidos do valor presente líquido positivo (VPL) em R $\$ 4.548 .806,73$, indicador relevante na tomada de decisão, conjugado com a taxa interna de retorno (TIR) de 10,28\%, acima do custo de oportunidade de $10 \%$, empregado como desconto do fluxo de caixa.

Apesar dos citados indicadores demonstrarem que se trata de um projeto factível, deve se considerar que em qualquer projeto há existência de riscos e incertezas, e aplicar técnica capaz de detectar o comportamento do modelo diante de tais eventos. Neste artigo foi adotado o método de simulação de Monte Carlo, que tem base probabilística.

No presente caso os elementos formadores da receita denotam considerável sensibilidade, e desta forma, detectou-se como variáveis críticas do projeto, o preço e o número de fainas vendidas (medida da atividade operacional), para aplicação da técnica supracitada.

Aplicando a simulação de Monte Carlo sobre o modelo em estudo, o resultado obtido apontou que $66 \%$ dos VPLs seriam positivos, demonstrando representatividade na indicação da viabilidade do projeto.

Nas análises apresentadas sobre o projeto desse estudo, verificou-se que o mesmo apresenta baixo grau de risco, seja quanto ao modelo determinístico, seja quanto ao modelo estatístico elaborado a partir das simulações. De tal sorte, conclui-se que o projeto é viável economicamente e recomenda-se a sua implementação.

O estudo propiciou uma proposta de análise econômica da qual não apenas as empresas do segmento de rebocadores poderão se beneficiar, mas também empresas de outras áreas, respeitando-se as devidas adaptações. À luz deste tema, buscou-se promover o diálogo entre o mundo acadêmico e empresarial, demonstrando-se, com isto, que é possível construir uma avaliação científica com o propósito de uma aplicação prática. Tal avaliação é constituída por elementos, que embora não sejam inovadores, é pouco disseminado no campo empresarial, o que muitas vezes torna a análise mais superficial e acaba impedindo que se focalize, de modo mais abrangente, os cenários que permeiam a realidade das empresas.

Como possibilidade de continuidade do trabalho poderia ser realizado um estudo de sensibilidade das variáveis do projeto, através de uma análise de stress test. Esses testes têm origem na engenharia ao redesenhar peças ou equipamentos para avaliar a degradação em condições extremas, além dos limites operacionais. Tal abordagem também vem sendo usada no mercado financeiro em diferentes áreas como gerenciamento de risco de carteiras, diante dos cenários futuros não previstos. Assim, o citado procedimento contribuiria para a análise dos limites do projeto sob novas perspectivas, aprimorando a resposta a possíveis adversidades que venham surgir no futuro.

\section{REFERÊNCIAS BIBLIOGRÁFICAS}

[1] BERGER, Flavio Roberto. Portos e Terminais Marítimos do Brasil. 2. ed. Santa Catarina: Bela Catarina, 2009.

[2] ANTAQ - ANUÁRIO ESTATÍSTICO - 2008 a 2017. Disponível em $<$ http://www.antaq.gov.br/portal/anuarios/portuario $>$. Acesso em 10 de maio de 2019.

[ 3 ] SCHACHTER, Richard David. Projeto de um Rebocador Portuário. Disponível em: $<$ www.deno.oceanica.ufrj.br/deno/prod_academic/relatorios/2016/Richard+Victor/ relat1/relatorio1.htm\#_msoanchor_1>. Ácesso em 11 de maio de 2019. 
[ 4 ] SILVA, Otávio Augusto Fragoso Alves da; GONÇALVES, Marcelo Campello Cajaty. Rebocadores Portuários. Rio de Janeiro: Conselho Nacional de Praticagem, 2002.

[ 5 ] RODRIGUES, Eduardo de Sá Fortes Leitão. Análise de investimentos e tomada de decisão. Rio de Janeiro: Publit, 2006.

[ 6 ] SAMANEZ, Carlos Patricio. Gestão de investimentos e geração de valor. São Paulo. Pearson. 2007.

[ 7 ] SANVICENTE, Antônio Zoratto. Administração Financeira. 3. ed. São Paulo: Atlas, 2007.

[ 8 ] BRUNI, Adriano Leal. Avaliações de investimentos. São Paulo: Atlas, 2008.

[9] HEYMANN, Mozart Caetano. Dissertação sobre Análise de Investimento para Construção de Rebocadores Azimutais. Rio de Janeiro, 2010.

[ 10 ] FISHER, Irving. The Theory of Interest. The Macmillan Company. NY. 1930.

[ 11 ] BREALEY. Richard A.; MYERS Stewart Clay. Princípios de Finanças Empresariais. 3. ed. Tradução H. C. Menezes; J. C. Costa. Lisboa: McGraw-Hill de Portugal, 1992.

[ 12 ] KNIGHT, Frank Hyneman. Risk, Uncertainty and Profit. London: Houghton Mifflin, 1921. (Second Edition, 1933).

[ 13 ] TITMAN, Sheridan; MARTIN, John David. Avaliação de projetos e investimentos: valuation. Tradução Heloísa Fontoura. Porto Alegre: Bookman, 2010.

[14] FERNANDES, César Augusto Becker de Araújo. Gerenciamento de riscos em projetos: usando a microsoft excel para realizar simulação de Monte Carlo, Paraná, dez, 2005. Disponível em: <www.bbbrothers.com.br/ scripts/Artigos/MonteCarloExcel.pdf>. Acesso em 15 de junho de 2010.

[ 15 ] WILSON SONS. Relatórios Anuais 2011 a 2018. Disponível em: $<$ ri,wilsonsons.com.br/publicações/relatórios-anuais>. Acesso em 15 de abril de 2019.

[16] FUNDO DA MARINHA MERCANTE. Financiamentos. Disponível em: <www.transportes.gov.br/conteudo/3855-financiamentos-com-recursos-do-fmm.html $>$. Acesso em 05 de maio de 2019.

[ 17 ] LABRUNA, Luiz. Empresa Erres Shiping. Consultoria Naval. Entrevista em 02, 09 e 14 de maio de 2019.

[ 18 ] PYNDICK, Robert Stephen; RUBINFELD, Daniel Lee. Microeconomia. 6. ed. Tradução Eleutério Prado; Telma Guimarães. São Paulo: Pearson Prentice Hall, 2006.

[ 19 ] RECEITA FEDERAL. Legislações. Disponível em: <receita.economia.gov.br/acessorapido/legislação/leis\#anosanteriores/Lein9430/96> . Acesso em: 12 de maio de 2019.

[ 20 ] ROSS, Stephen A.; WESTERFIELD, Randolph W.; JAFFE, Jeffrey F. Administração financeira. Tradução Antônio Z. Sanvicente. São Paulo: Atlas, 1995.

[ 21 ] SPIEGEL, Murray Ralph. Estatística. 2. Ed. São Paulo: McGraw-Hill do Brasil, 1985.

[ 22 ] BUSSAB, Wilton de Oliveira; MORETTIN, Pedro Alberto. Estatística Básica. 5. Ed. São Paulo: Saraiva, 2003. 